handing over all sorts of rights to others (as in the case of surgery) if we think the consequence is some good. If this is granted, the question then is: can our own death constitute a good? I see no reason why not if a reduction of suffering can count as a good.

Another interesting point (page 74) raised by Callahan is that physicians, in engaging in PAS, are stepping outside their normal areas of competence and license. In the cases of PAS physicians are being asked to address not a medical problem, but a problem of life, that of dying. The answer is that this boundary has never been very clear, and to rule out anything addressing a problem of life would make much of psychiatry dubious. Perhaps it is. But more damagingly one might reflect as follows. True, dying itself is not an illness, but then breaking one's leg is not illness, or accidentally blinding oneself. They are in a sense problems of life. It might be said that the question here is promoting health, but it seems a mis-description to say that having an untreated blind eye is a case of unhealthiness. If you go around for long enough you are probably going to injure yourself. However long is the time in between, if you are born, you are going to end up dying. Should the condition of dying be addressed by physicians? I am not sure why not unless we are going to eliminate other things physicians routinely do. In any case the question of whether physicians should perform these acts may be a red herring; again, we could license a special group of people to do it. This may look odd, or even frightening. But it must be borne in mind that if assisted suicide became common, informal social mechanisms would arise - rather as they have in the case of birth and marriage - which simply because of the illegality or rarity of assisted suicide at present cannot exist.

This is a fine book. It is, as I say, well balanced. Physicians for whom philosophical discussion can seem too abstract will read it with profit.

JOHN SHAND

The Open University

\section{Practical Reasoning in Bioethics}

James F Childress, Bloomington, Indiana University Press, 1997, 386 pages, $£ 33.50$, (hb).
This collection of sixteen essays covers Childress's work in bioethics since the 1970s. Most of the material here has been previously published but there are substantial revisions, updates and responses to criticism. This revision has resulted in a book with a coherent structure, not just a collection of essays. The central theme is the principles approach to bioethics which is clarified, defended, and modified in the present text. Childress's approach, which is frequently described as "principlism", found expression in earlier books, such as The Principles of Biomedical Ethics, co-authored with Tom Beauchamp.

The substantive perspective of these essays, says Childress, is that of "liberal communitarianism", which is "founded on a strong presumption in favour of respect for personal autonomy" (page xi). However, Childress insists that this principle can "sometimes be overridden for the sake of communal goods" (page xi).

The book is organised into five sections which break down as follows. Part One outlines the principles approach and defends one particular version against critics, including casuists, feminists, narrativists and virtuists. Critics of principlism have often argued that the centrality of metaphor, analogy and symbolism, in health care discourse is incompatible with a principles approach. But Childress disagrees, and in the early essays he demonstrates how metaphorical discourse can exist in close relation with principles and rules derived from them. The metaphor of warfare, for example, can be instructive in understanding conceptions of what should be done in health care; note how it determines priorities and depicts the role of the health care professional in our society. Likewise, analogies - such as those often drawn between the holocaust and proposals for the withholding of some forms of life-prolonging therapy - can either illuminate or distort moral discourse according to the manner in which they are employed. The conclusion that is drawn from Childress's analysis of metaphorical and analogical reasoning is that it is valuable when conducted within a framework of principles and rules.

The second part focuses on the principle of autonomy, its implications and limitations, with essays on regulations in nursing homes, the provision of information to cancer patients, and the debate on mandatory HIV screening and testing, where metaphors of the "war" against AIDS are frequently cited in support of proposals to curtail individual autonomy.

Three essays in Part Three are concerned with the termination of lifesustaining treatment, with particular reference to the debate over the withdrawal of nutrition and hydration from certain categories of patients. The issues highlighted in Part Four include the debate on the allocation of health care and decisions concerning criteria for selective treatment. Two essays on intensive care and organ transplantation offer a comprehensive account of the principles approach in applied bioethics. One essay on the right to health care in a democratic society is particularly critical of the American failure to organise a comprehensive health care system. In Part Five the issue of transplant ethics is re-visited, and Childress assesses criteria for obtaining organs, the notion of human body parts as property, and proposals for a commercial market in organs. The final essay touches on some of the broader issues related to transplantation and research on fetal tissue.

This is a valuable clarification, re-statement and defence of principlism as an approach to applied ethics. It is strongly recommended to many teachers of bioethics who may have misled their students regarding principlism with the use of diagrams purporting to sketch the relationship between theories, principles, rules, and particular moral judgments. The overhead projector may be a useful teaching aid but simplified diagrams are no substitute for the complexities of moral inquiry.

DAVID LAMB University of Birmingham

\section{Do We Still Need Doctors?}

John Lantos, New York/London, Routledge, 1997, 214 pages, $£ 17.99$.

John Lantos is a paediatrician, teacher and bioethicist at the University of Chicago. In this book he explores the past, present and future roles of doctors as we face the millennium and beyond. Richly interwoven with personal and professional anecdotes, case histories, literary examples and moral arguments, this is an intensely personal, thoughtful and thoughtprovoking book. The issues, dilemmas 
and inconsistencies which Dr Lantos probes are not unique to American medicine and, with the increasing move to globalism, they have relevance and resonance for others. Indeed, the past ten years in the United Kingdom have seen a re-organisation of the National Health Service (NHS) on purchaser/provider lines, establishment of evidence-based medicine and clinical guidelines, and the beginnings of managed care. We too have been preoccupied with the political, sociological and economic factors that $\mathrm{Dr}$ Lantos categorises, with the human genome project, the advances of technology and bioethics, and we have witnessed the decline of the generalist be $s /$ he surgeon, physician or paediatrician.

Each chapter uses a broadly similar format to deal with specific issues which face doctors but seen through a paediatrician's eyes. As such, some of the particular problems-for example those related to paternalism encompassed in the chapters on Truth, story, fiction and lies and On mistakes and truth telling - are perhaps of less interest to an adult specialist. As Dr Lantos remarks: "As with most modern bioethical paradigms all bets are off when it comes to paediatrics". $\mathrm{He}$ argues that there is a dichotomy between legal obligations which are largely owed to the parents and moral obligations which are largely but not entirely owed to the child. It is this intriguing distinction which will interest paediatricians because it recurs throughout the book. There are accounts of fractionation of total care once provided by doctors, of shifts in management structure, of medical practice which is increasingly dehumanised and increasing economically and legally orientated. $\mathrm{He}$ describes the "hollowing out" of doctors and the alienation which may accompany the practice of high technology medicine and ponders whether this need always be the price that we pay for progress.

Anecdotes and case histories are used to provide the power to move and to lead us to question what we do in relation to our own practice. The description of an unsuccessful attempt to resuscitate a close relative, for example, both illustrates notions of utility and helps to affirm and value the life of someone who is dying. The case of a child with campomelic dwarfism helps focus our views on futility and what may be in a child's best interests - and who decides what those best interests are. It is interesting to speculate what would happen to this particular child in the UK if a court were to apply the UK standards of best interests; this would be especially relevant given the recent publication of a Framework of Practice for Withdrawing or Withholding Life Sustaining Treatment by the Royal College of Paediatrics and Child Health. Indeed the whole issue of best interests raises important questions as to whether best interests standards can ever be applied from a child's perspective or be separate from our own and society's views on the future of children. I would have liked more analysis in this particular chapter.

Naturally, Lantos is concerned with how future doctors should be educated and those who contemplate studying medicine or are studying it could do a lot worse than read this book. One chapter is largely devoted to one of Lantos's mentors who ironically died of liver failure in the largest liver transplant unit in the world. Many doctors will have known and appreciated such teachers as Ken Schuit, but how often is their workload and contribution valued? In a passage which echoes some of the sentiments expressed by Earl Spencer at The Princess of Wales's funeral, Lantos wonders whether morality is something that we can't define and which we can only recognise when it is gone. Lantos finally examines the inexorable march of medicinal progress and the inconsistencies, incompatibilities and ambivalence which surround it. $\mathrm{He}$ questions whether, for example, randomised controlled trials can produce answers to all the questions we wish to ask. He discusses whether medicine is a moral enterprise with its own values or a technical exercise which is morally neutral and argues that our response will condition the kind of doctors which we want. In a significant passage he regards "the doctor who must gain informed consent according to a legally defined protocol in order to provide treatment that the patient's insurance company [substitute provider] has approved because it is the most cost effective and who then provides the treatment according to a practice guideline based on valid outcome studies is a very different creature from any doctor who has ever practised before". Indeed he is, if he practises without the art and humanity of the physician and without taking into account the intricacies of the doctor-patient relationship.

The last clinical example, that of a teenager with sickle cell disease whom
Lantos suspects has an eating disfक् der, is perhaps the most telling in book. This is largely because it enc $\bar{p}$ sulates the frustration of a doctor who, though a good doctor by most sta ards, cannot relieve the pain he sejes behind a patient's eyes.

There are a few caveats. Those wito wish formulaic answers in this bogk will not find them; this is a book? provide questions, to give us pause for thought, rather than to provide solutions. It is written from an American perspective and a glossary of some of the terms might be helpful. It woygd be difficult to judge (as a paediatician) what impact this book wo make on non-paediatricians or nadclinicians and indeed it is not clear for whom this book is intended. However, all those who care about the direction in which medicine is going and all those who believe that there is artoas well as science in medicine should read it. Those who neither believe nor care should also read this book to ofen their eyes as to what many doctors and patients feel.

VICTOR LAREHHER

Queen Elizabeth Hospital, Hacknej

London ES

\section{Living With One's Past. Personal Fates and Moral Pain}

Norman S Care, Lapham, Marylan Rowman and Littlefield, 1996, xiii 雱

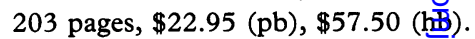

This book is undoubtedly erudite. only is there a breadth of philosophical learning, but, amongst others, Cam Tolstoy and William James are gimen an airing, and some perceptive comments on Arthur Miller's play Deat a Salesman are woven into the text.So I enjoyed reading it and found plengty that was stimulating. But I was ploft with a question about its overall coherence as a book.

Chapter one establishes that the human condition is such that manpof us are or will be condemned by ?ur pasts to be without peace of minnd" (page 24). The force of the auth immediate question to himself, ब्ब what?", is not tempered by his adrotssion that "living with one's past If a problem without a solution" (page 24). Somewhat later he states that people are, in part, their histories, which may contain genetic and 